\title{
Fully-Differential Multifunctional Electronically Configurable Fractional-Order Filter with Electronically Adjustable Parameters
}

\author{
Lukas Langhammer ${ }^{1}$, Roman Sotner ${ }^{1}$, Jan Dvorak ${ }^{1}$, Tomas Dostal ${ }^{2}$ \\ ${ }^{1}$ Faculty of Electrical Engineering and Communication, Brno University of Technology, \\ Technicka 12, 61600, Brno, Czech Republic \\ ${ }^{2}$ Department of Technical Studies, College of Polytechnics, \\ Tolsteho 16, 58601, Jihlava, Czech Republic \\ langhammer@phd.feec.vutbr.cz
}

\begin{abstract}
The paper presents a novel solution of a fullydifferential $1+\alpha$ fractional-order filter. The filter can provide low-pass, high-pass, band-pass and band-stop transfer functions without a necessity of a circuitry change (filter is electronically configurable). The proposed filter also provides the electronic control of its parameters such as the fractionalorder of the filter, pole frequency as well as quality factor. Operational Transconductance Amplifiers (OTAs), Adjustable Current Amplifiers (ACAs) and Fully-Differential Current Follower (FD-CFs) were used in the proposal. The proposal is supported by PSpice simulations using transistor-level models of used active elements.
\end{abstract}

Index Terms-Electronic controllability; Filtering; Fractional calculus; Frequency control.

\section{INTRODUCTION}

Recently, many researches have focused on the matter of fractional-order circuits due to their possible utilization for many new potential applications in fields of biochemistry, medicine and electrical engineering [1]. The research of the fractional-order circuits includes frequency filters [2]-[11], oscillators [12], [13], controllers [14] and regulators [15], for example. In comparison to conventional (integer-order) filters, the transition between the pass-band and stop-band area of a fractional-order filter is given by relation $20 \cdot(n+\alpha) \mathrm{dB} /$ decade, where parameter $\alpha$ brings the fractional term to this expression [4].

The design of the fractional-order filters is approachable by two conceivable methods. The first approach is based on utilization of so-called Fractional-Order Elements (FOE), fractional-order capacitors, specifically. They are known also as so-called constant phase elements (CPEs). Due to the absence of commercial availability of the FOEs, the substitutions of these elements by specifically designed RC ladder networks were developed [2], [7]. The disadvantage of this approach consists in changes of the topology of the proposed $\mathrm{CPE}$ as well as values of all passive components

Manuscript received 4 February, 2018; accepted 24 July, 2018

Research described in this paper was financed by the National Sustainability Program under grant LO1401. For the research, infrastructure of the SIX Center was used. in order to adjust its order, operational bandwidth and phase ripple. The other possible approach to the design of fractional-order filters supposes an approximation of the given fractional-order Laplacian operator $\boldsymbol{s}^{\alpha}$ by a suitable integer-order filter function of higher order [4]. Fractionalorder filters, designed by this way, can be easily constructed by commercially available active and passive elements. The electronic control of the order and other parameters of the filter, when employing controllable active elements in the circuit structure, brings clear advantages of this way.

Most of the recent proposals introduce fractional-order filters that usually do not provide more than one transfer function simultaneously. From the previously reported fractional-order filters, structures in [2]-[5] provide only low-pass (LP) function. Paper [6] describes a proposal of filter which offers only high-pass (HP) function. Papers [7][9] present structures which provide LP and band-pass (BP) functions and [10] offers LP and HP functions, nonetheless, in order to obtain the other function, the circuitry must be modified, or the replacement of passive parts within the structure is necessary. Only [11] proposes a structure which provides (LP), (HP), (BP) and band-stop (BS) functions simultaneously without necessity to modify its topology.

The fractional-order filter proposed in this paper has been designed using operational transconductance amplifiers (OTAs), adjustable current amplifiers (ACAs) together with fully-differential current followers (FD-CFs). The proposed filter offers LP, BP, HP and BS transfer function from the same circuit topology by simple electronic reconfiguration of electronically adjustable parameters. Furthermore, the filter provides the electronic control of its order, pole frequency, and also quality factor. The filter is designed in its fully-differential form due to the advantages of the fully-differential (F-D) topologies which can be achieved in particular cases. F-D structures bring some advantages such as greater dynamic range of the processed signals, better power supply rejection ratio, lower harmonic distortion and greater attenuation of common-mode signal in comparison to the single-ended (S-E) circuits [16]. However, doubled complexity (number of elements) accompanies discussed benefits. 
TABLE I. COMPARISON OF THE PREVIOUSLY REPORTED FRACTIONAL-ORDER FILTERS

\begin{tabular}{|c|c|c|c|c|c|c|c|c|c|}
\hline 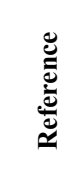 & 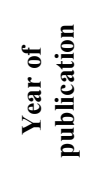 & 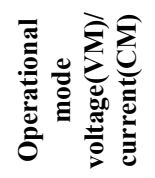 & 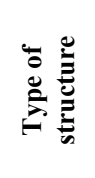 & 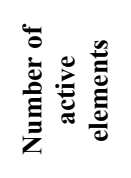 & 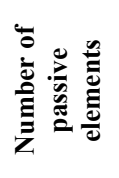 & 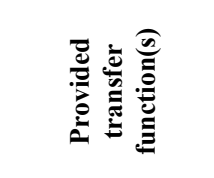 & 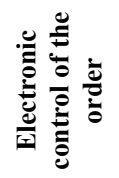 & 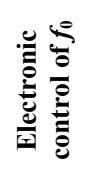 & 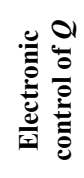 \\
\hline [2] & 2015 & $\mathrm{VM}$ & S-E & 3 & 8 & LP & No & No & No \\
\hline [3] & 2016 & $\mathrm{VM}$ & S-E & 4 & 13 & LP & No & No & No \\
\hline [4] & 2018 & $\mathrm{CM}$ & S-E & 6 & 3 & LP & Yes & Yes & No \\
\hline$[5]$ & 2016 & $\mathrm{VM}$ & S-E & 5 & 10 & LP & No & No & No \\
\hline [6] & 2016 & $\mathrm{CM}$ & S-E & 6 & 3 & HP & Yes & Yes & No \\
\hline [7] & 2012 & $\mathrm{VM}$ & S-E & 3 & 8 & LP, BP* & No & No & No \\
\hline [8] & 2017 & $\mathrm{CM}$ & S-E & 3 & 2 & LP, BP* & Yes & No & No \\
\hline [9] & 2011 & $\mathrm{VM}$ & S-E & 2 & 13 & LP, BP* & No & No & No \\
\hline$[10]$ & 2016 & $\mathrm{VM}$ & S-E & 4 & 14 & LP, HP* & No & No & No \\
\hline$[11]$ & 2017 & $\mathrm{VM}$ & S-E & 8 & 19 & LP, HP, BP, BS & Yes & No & No \\
\hline Fig. 1 & - & $\mathrm{CM}$ & F-D & 9 & 6 & LP, HP, BP, BS & Yes & Yes & Yes \\
\hline
\end{tabular}

Note: *The other function is either taken from a different circuit structure or the replacement of passive parts of the RC ladder network is necessary.

Table I provides a comparison of relevant previously reported fractional-order filtering structures.

\section{Multifunctional Fractional-ORdER Filter PROPOSAL}

The proposed multifunctional fractional order filter is based on the approximation of Laplacian operator $\boldsymbol{s}^{\alpha}$ by recently presented $4^{\text {th }}$-order approximation [17] which is applied onto the current mode $n^{\text {th }}$-order universal filter based on the inverse follow the leader feedback (IFLF) structure from [18]. The approximation from [17] allows controlling the quality factor of the resulting fractionalorder function thanks to the appropriate $K$ parameters selection. Parameters $K$ are shaping the transition between the pass-band and stop-band region while keeping the required fractional-order, Butterworth characteristics of the function and desired quality factor. B-type $K$ coefficients from [17] were used in this case. Individual calculations for each obtainable transfer function are not included in the paper due to their extensive volume.
The proposed F-D multifunctional fractional-order filter (Fig. 1) utilizes three balanced-output transconductance amplifiers (BOTAs) [19], four adjustable current amplifiers (ACAs) [20] and two fully-differential current followers (FD-CF) [21]. All active elements used for the PSpice simulation included in the paper were represented by transistor-level models implemented in CMOS $0.18 \mu \mathrm{m}$ technology supplied by $\pm 1 \mathrm{~V}$. The BOTA element can be described by the equation $I_{\mathrm{OUT} \pm}= \pm g_{\mathrm{m}}\left(V_{\mathrm{IN}+}-V_{\mathrm{IN}-}\right)$, where $g_{\mathrm{m}}$ labels the transconductance of this element. The used simulation model was taken from [19]. The transconductance of this particular implementation of the BOTA element is controlled electronically by DC current. The behavior of the ACA element is defined by the relation $I_{\mathrm{OUT} \pm}= \pm B\left(I_{\mathrm{IN}+}-I_{\mathrm{IN}-}\right)$, where $B$ is the current gain controllable by DC current in this particular case. The simulation model of the ACA element was taken from [20]. The FD-CF element is described by relation $I_{\mathrm{OUT} \pm}= \pm\left(I_{\mathrm{IN}+}-\right.$ $I_{\mathrm{IN}-}$ ) and its simulation model is described in [21].

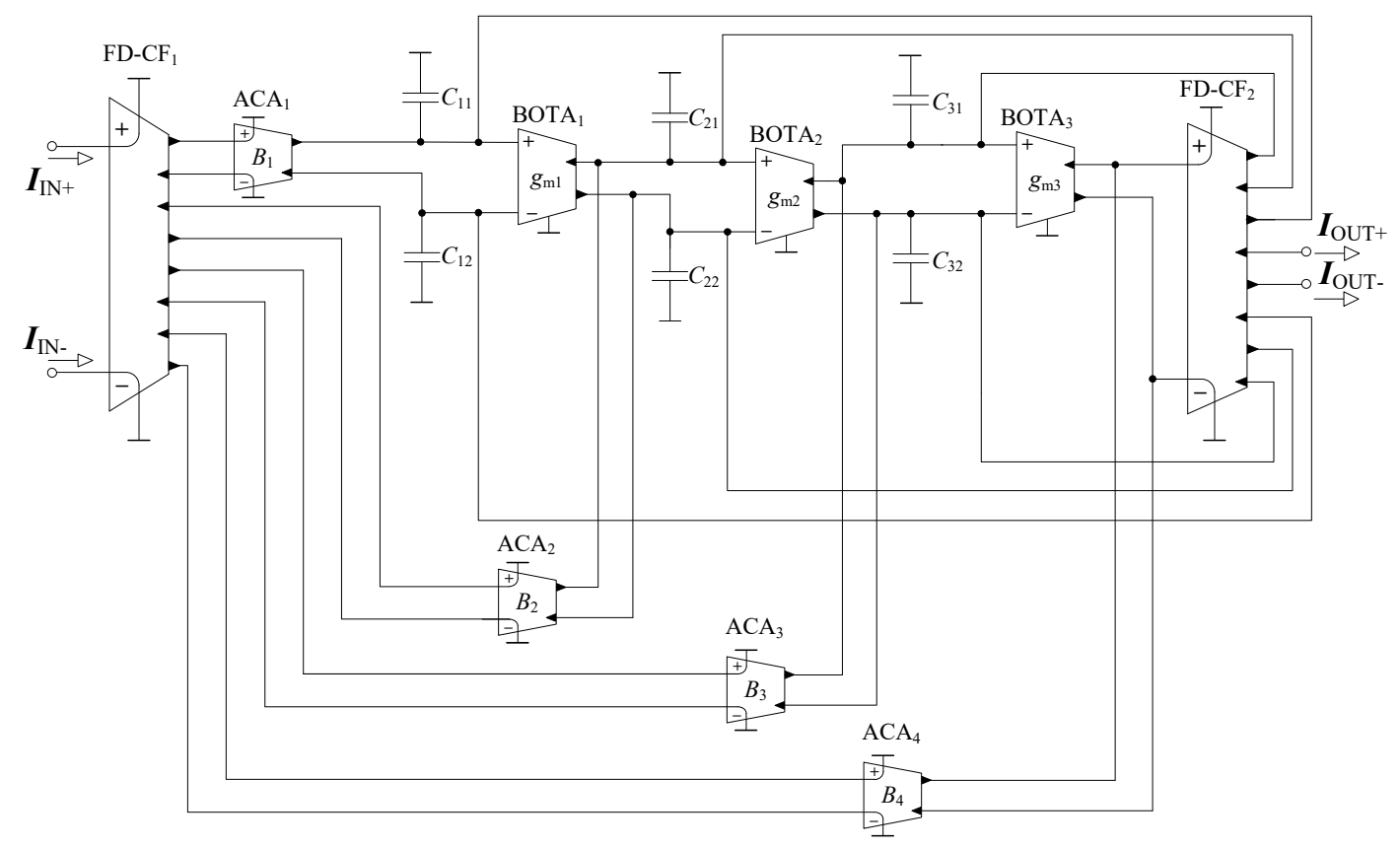

Fig. 1. Scheme of the F-D 3rd-order CM filter leading to approximated multifunctional fractional-order filter. 
The transfer function of the proposed filter from Fig. 1 is given by $K(\boldsymbol{s})=N(\boldsymbol{s}) / D(\boldsymbol{s})$, where:

$$
\begin{gathered}
N(\boldsymbol{s})=B_{4} \boldsymbol{s}^{3}+\frac{B_{3} g_{m 3}}{C_{3}} \boldsymbol{s}^{2}+ \\
+\frac{B_{2} g_{m 2} g_{m 3}}{C_{2} C_{3}} \boldsymbol{s}+\frac{B_{1} g_{m 1} g_{m 2} g_{m 3}}{C_{1} C_{2} C_{3}}, \\
D(\boldsymbol{s})=\boldsymbol{s}^{3}+\frac{g_{m 3}}{C_{3}} \boldsymbol{s}^{2}+\frac{g_{m 2} g_{m 3}}{C_{2} C_{3}} \boldsymbol{s}+\frac{g_{m 1} g_{m 2} g_{m 3}}{C_{1} C_{2} C_{3}} .
\end{gathered}
$$

The resulting fractional-order function is dependent on the actual configuration of current gains $B_{1}-B_{4}$, where $B_{2}-B_{4}$ influence HP function, $B_{1}-B_{3}$ are important for LP and BP function, $B_{1}-B_{4}$ for the $\mathrm{BS}$ functions. The order, pole frequency $f_{0}$ and quality factor $Q$ of the filter can be controlled electronically without affecting each other by suitable setting of values of transconductances $g_{\mathrm{m} 1}, g_{\mathrm{m} 2}$, $g_{\mathrm{m} 3}$ and current gains $B_{1}, B_{2}, B_{3}$ and $B_{4}$. Due to the fact that the floating capacitors are not suitable for the implementation and integrability, the capacitors $C_{1}, C_{2}, C_{3}$ in the circuit structure (which would be floating) are intended as separated grounded capacitors $C_{11}, C_{12}, C_{21}, C_{22}$, $C_{31}$ and $C_{32}$.

\section{CIRCUIT VERIFICATION}

The PSpice simulations of the proposed filter have been carried out using transistor-level models as mentioned in the previous section.

Following values of passive and active components and values of other parameters were selected to be the default values used for the PSpice simulations: the initial pole frequency $f_{0}=100 \mathrm{kHz}$, the starting value of the quality factor $Q=0.707$ (Butterworth approximation), the default value of the order $n=1.5(\alpha=0.5)$, values of capacitors (which are the same for all settings) $C_{11}=C_{12}=1020 \mathrm{pF}$, $C_{21}=C_{22}=4200 \mathrm{pF}$ and $C_{31}=C_{32}=940 \mathrm{pF}$.

Figure 2 shows the obtainable transfer functions (HP, BP, LP, BS) for default values stated above. The values of the remaining parameters $\left(g_{\mathrm{m} 1}-g_{\mathrm{m} 3}\right.$ and $\left.B_{1}-B_{4}\right)$ are listed in Table II. The obtained simulation results (solid lines) are compared in Fig. 2 with the theoretical expectations (dashed lines). The differences between the simulations and the theory at lower and higher frequencies are caused by nonideal features of used simulation models. That applies for all simulation results presented in the paper.

TABLE II. USED VALUES OF INDIVIDUAL FILTER PARAMETERS FOR DIFFERENT TRANSFER FUNCTIONS.

\begin{tabular}{|c|c|c|c|c|}
\hline $\begin{array}{c}\text { Function/ } \\
\text { parameter }\end{array}$ & $\begin{array}{c}\text { Low } \\
\text { pass }\end{array}$ & Band pass & $\begin{array}{c}\text { High } \\
\text { pass }\end{array}$ & Band stop \\
\hline$g_{\mathrm{m} 1}[\mathrm{mS}]$ & 0.105 & 0.105 & 0.081 & 0.105 \\
\hline$g_{\mathrm{m} 2}[\mathrm{mS}]$ & 1.199 & 1.200 & 1.452 & 1.200 \\
\hline$g_{\mathrm{m} 3}[\mathrm{mS}]$ & 1.167 & 1.170 & 0.898 & 1.170 \\
\hline$B_{1}[-]$ & 0.496 & 0.091 & - & 0.500 \\
\hline$B_{2}[-]$ & 0.326 & 0.298 & 0.030 & 0.351 \\
\hline$B_{3}[-]$ & 0.030 & 0.136 & 0.326 & 0.229 \\
\hline$B_{4}[-]$ & - & - & 0.496 & 0.393 \\
\hline
\end{tabular}

Figure 3 demonstrates the electronic control of the order of the proposed filter at LP response for three different values of parameter $\alpha(0.3,0.5,0.7)$ while $f_{0}=100 \mathrm{kHz}$ and
$Q=0.707$. Used values of transconductances and current gains for selected values of $\alpha$ are summarized in Table III. Values of the order obtained from simulations are stated in the graph legend (values in brackets). The obtained simulation results (solid lines) are close to the theory (black dashed lines).

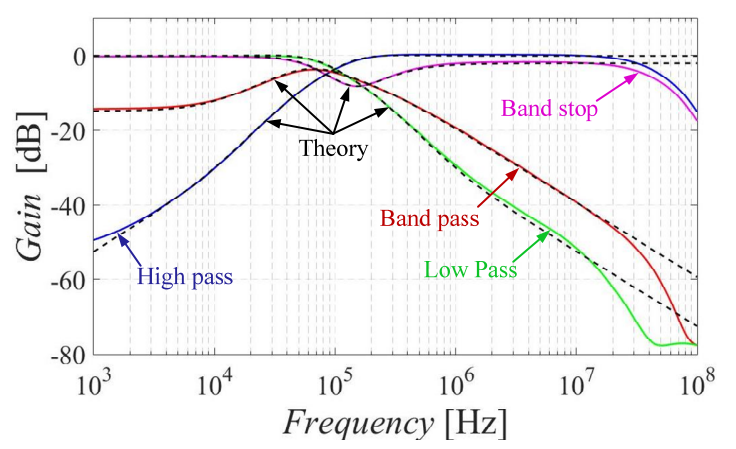

Fig. 2. Frequency responses of HP, BP, LP and BS transfer functions for $\alpha=0.5, f_{0}=100 \mathrm{kHz}$ and $Q=0.707$.

Figure 4 demonstrates a possibility of the electronic control of the pole frequency of the proposed filter by change of transconductances $g_{\mathrm{m} 1}-g_{\mathrm{m} 3}$. BS function was selected for illustration in this case. The tunability of $f_{0}$ is tested for three different values $(50 \mathrm{kHz}, 100 \mathrm{kHz}, 150 \mathrm{kHz})$ when the order of the filter is set to 1.9 and $Q=0.707$. The transconductances and current gains for tested values of $f_{0}$ are stated in Table IV. Values of $f_{0}$ obtained from simulation results (values in brackets) are in good agreement with the theory. The difference slightly increases with increasing pole frequency.

TABLE III. USED VALUES OF INDIVIDUAL LP FILTER PARAMETERS IN CASE OF ORDER CONTROL.

\begin{tabular}{|c|c|c|c|}
\hline $\boldsymbol{\alpha}[-] /$ parameter & $\mathbf{0 . 3}$ & $\mathbf{0 . 5}$ & $\mathbf{0 . 7}$ \\
\hline$g_{\mathrm{m} 1}[\mathrm{mS}]$ & 0.091 & 0.105 & 0.195 \\
\hline$g_{\mathrm{m} 2}[\mathrm{mS}]$ & 1.139 & 1.199 & 1.238 \\
\hline$g_{\mathrm{m} 3}[\mathrm{mS}]$ & 1.150 & 1.167 & 1.035 \\
\hline$B_{1}[-]$ & 0.494 & 0.496 & 0.497 \\
\hline$B_{2}[-]$ & 0.366 & 0.326 & 0.284 \\
\hline$B_{3}[-]$ & 0.048 & 0.30 & 0.015 \\
\hline$B_{4}[-]$ & - & - & - \\
\hline
\end{tabular}

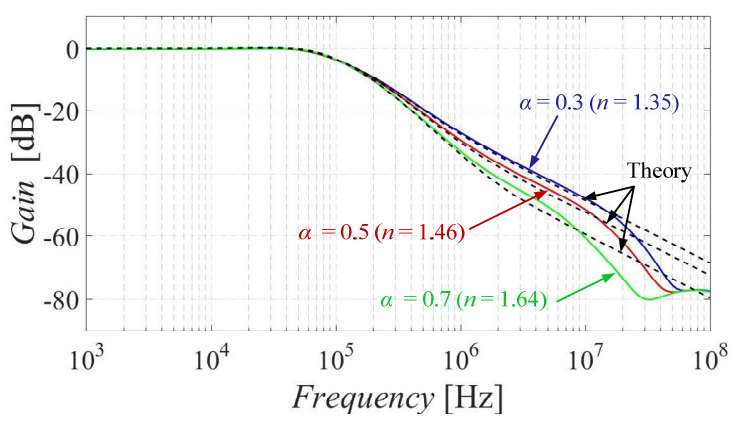

Fig. 3. Demonstration of the controllability of the order for $f_{0}=100 \mathrm{kHz}$ and $Q=0.707$.

TABLE IV. USED VALUES OF INDIVIDUAL BS FILTER PARAMETERS IN CASE OF POLE FREQUENCY CONTROL.

\begin{tabular}{|c|c|c|c|}
\hline $\boldsymbol{f}_{\boldsymbol{b}}[\mathbf{k H z}] /$ parameter & $\mathbf{5 0}$ & $\mathbf{1 0 0}$ & $\mathbf{1 5 0}$ \\
\hline$g_{\mathrm{m} 1}[\mathrm{mS}]$ & 0.064 & 0.127 & 0.191 \\
\hline$g_{\mathrm{m} 2}[\mathrm{mS}]$ & 0.653 & 1.310 & 1.960 \\
\hline$g_{\mathrm{m} 3}[\mathrm{mS}]$ & 0.436 & 0.872 & 1.308 \\
\hline$B_{1}[-]$ & \multicolumn{3}{|c|}{0.5} \\
\hline$B_{2}[-]$ & 0.233 \\
\hline$B_{3}[-]$ & \multicolumn{3}{|c}{0.194} \\
\hline$B_{4}[-]$ & 0.485 \\
\hline
\end{tabular}




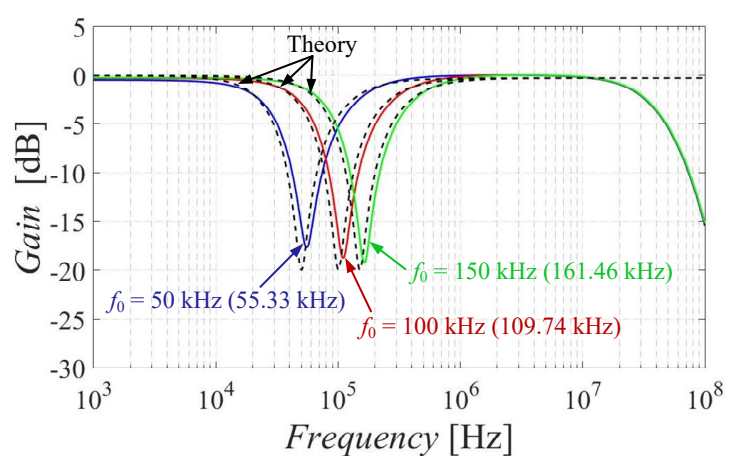

Fig. 4. Demonstration of the controllability of the pole frequency for $n=1.9$ and $Q=0.707$.

The electronic controllability of the quality factor of the proposed filter is tested in Fig. 5 (HP function selected as example) for three different values $(0.707,1.41$ and 2.12$)$ while $f_{0}=100 \mathrm{kHz}$ and $n=1.5$. Table $\mathrm{V}$ contains used values of $g_{\mathrm{m}}$ and $B$ parameters depending on selected value of $Q$. Values of $Q$ obtained from simulation results (values in brackets) and the theoretical expectations (black dashed lines) can be compared in the graph legend. The values of $Q$ obtained from simulation are slightly below the theoretical expectations.

TABLE V. USED VALUES OF INDIVIDUAL HP FILTER PARAMETERS IN CASE OF QUALITY FACTOR CONTROL.

\begin{tabular}{|c|c|c|c|}
\hline $\boldsymbol{Q}[-\mathrm{-} /$ parameter & $\mathbf{0 . 7 0 7}$ & $\mathbf{1 . 4 1}$ & $\mathbf{2 . 1 2}$ \\
\hline$g_{\mathrm{m} 1}[\mathrm{mS}]$ & 0.081 & 0.154 & 0.203 \\
\hline$g_{\mathrm{m} 2}[\mathrm{mS}]$ & 1.452 & 1.321 & 1.271 \\
\hline$g_{\mathrm{m} 3}[\mathrm{mS}]$ & 0.898 & 0.631 & 0.537 \\
\hline$B_{1}[-]$ & - & - & - \\
\hline$B_{2}[-]$ & 0.030 & 0.046 & 0.055 \\
\hline$B_{3}[-]$ & 0.326 & 0.457 & 0.525 \\
\hline$B_{4}[-]$ & 0.496 & 0.488 & 0.480 \\
\hline
\end{tabular}

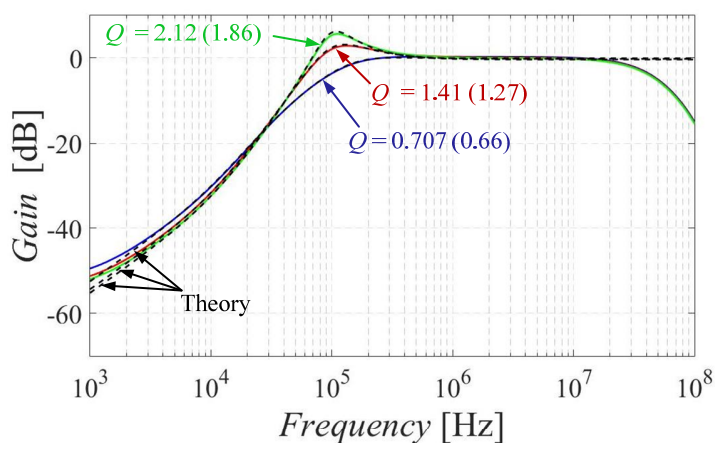

Fig. 5. Demonstration of the controllability of the quality factor for $f_{0}=100$ $\mathrm{kHz}$ and $n=1.5$.

\section{CONCLUSIONS}

All three electronic controllabilities were proved operating appropriately and the obtained results are close to the theoretical expectations. The theoretical tested orders were $1.3,1.5,1.7$, obtained values were $1.35,1.46$ and 1.64 . The controllability of $f_{0}$ was tested for values $50 \mathrm{kHz}$, $100 \mathrm{kHz}, 150 \mathrm{kHz}$, when simulations yield $55.33 \mathrm{kHz}$, $109.74 \mathrm{kHz}$ and $161.46 \mathrm{kHz}$. The tested $Q$ was set to 0.707 , $1.41,2.12$ while obtained values are $0.66,1.27$ and 1.86 .

\section{REFERENCES}

[1] A. S. Elwakil, "Fractional-order circuits and systems: An emerging interdisciplinary research area", IEEE Circuits and Systems Magazine, vol. 10, pp. 40-50, 2010. DOI: 10.1109/MCAS.2010.938637.
[2] T. J. Freeborn, B. Maundy, A. S. Elwakil, "Approximated fractional order Chebyshev lowpass filters", Mathematical Problems in Engineering, vol. 2015, pp. 1-7, 2015. DOI: 10.1155/2015/832468.

[3] G. Tsirimokou, S. Koumousi, C. Psychalinos, "Design of fractionalorder filters using current feedback operational amplifiers", Journal of Eng. Science \& Techn. Review, vol. 9, pp. 77-81, 2016.

[4] L. Langhammer, J. Dvorak, J. Jerabek, J. Koton, R. Sotner, "Fractional-order low-pass filter with electronic tunability of its order and pole frequency", Journal of Electrical Engineering, vol. 69, no. 1, 2018, pp. 3-13. DOI: 10.1515/jee-2018-0001.

[5] F. Khateb, D. Kubanek, G. Tsirimokou, C. Psychalinos, "Fractionalorder filters based on low-voltage DDCCs", Microelectronics Journal, vol. 50, pp. 50-59, 2016. DOI: 10.1016/j.mejo.2016.02.002.

[6] J. Jerabek, R. Sotner, J. Dvorak, L. Langhammer, J. Koton, "Fractional-order high-pass filter with electronically adjustable parameters", in Proc. 21st 2016 Int. Conf. on Applied Electronics, Pilsen, Czech Republic, 2016, pp. 111-116. DOI: 10.1109/AE.2016.7577253.

[7] T. J. Freeborn, B. Maundy, A. S. Elwakil, "Fractional-step TowThomas biquad filters", Nonlinear Theory and Its Applications IEICE, vol. 3, no. 3, pp. 357-374, 2012. DOI: 10.1587/nolta.3.357.

[8] R. Verma, N. Pandey, R. Pandey, "Electronically tunable fractional order filter", Arabian Journal for Science and Engineering, vol. 42, pp. 3409-3422, 2017. DOI: 10.1007/s13369-017-2500-8.

[9] B. Maundy, A. S. Elwakil, T. J. Freeborn, "On the practical realization of higher-order filters with fractional stepping", Signal Processing, vol. 91, no. 3, pp. 484-491, 2011. DOI: 10.1016/j.sigpro.2010.06.018.

[10] J. Koton, D. Kubanek, K. Vrba, A. Shadrin, P. Ushakov, "Universal voltage conveyors in fractional-order filter design", in Proc. Int. Conference on Telecommunications and Signal Processing, Vienna, Austria, 2016, pp. 593-598. DOI: 10.1109/TSP.2016.7760950.

[11] G. Tsirimokou, R. Sotner, J. Jerabek, J. Koton, C. Psychalinos, "Programmable analog array of fractional-order filters with CFOAs", in Proc. 40th Int. Conf. Telecommunications and Signal Processing (TSP 2017), Barcelona, Spain, 2017, pp. 706-709. DOI: 10.1109/TSP.2017.8076079.

[12] A. G. Radwan, A. M. Soliman, A. S. Elwakil, "Fractional-order sinusoidal oscillators: Four practical circuit design examples", Int. Journal of Circuit Theory and Applications, vol. 36, no. 4, pp. 473492, 2008. DOI: 10.1002/cta.453.

[13] M. E. Fouda, A. Soltan, A. G. Radwan, A. M. Soliman, "Fractionalorder multi-phase oscillators design and analysis suitable for higherorder PSK applications", Analog Integrated Circuits and Signal Processing, vol. 87, no. 2, pp. 301-312, 2016. DOI: 10.1007/s10470016-0716-2.

[14] I. Podlubny, I. Petr, B. M. Vinagre, P. O'Leary, L. Dorcak, “Analogue realizations of fractional-order controllers", Nonlinear Dynamics, vol. 29, no. 1, pp. 281-296, 2002. DOI: 10.1023/A:1016556604320.

[15] J. Petrzela, "Design of complex fractional-order immittances for simple PID regulation", in Proc. the 40th Int. Conf. Telecommunications and Signal Processing (TSP 2017), Barcelona, Spain, 2017, pp. 283-288. DOI: 10.1109/TSP.2017.8075988.

[16] J. Jerabek, K. Vrba, "Comparison of the fully-differential and singleended solutions of the frequency filter with current followers and adjustable current amplifier", in Proc. $11^{\text {th }}$ Int. Conf. Networks (ICN 2012), France, 2012, pp. 50-54.

[17] D. Kubanek, T. J. Freeborn, “ $(1+\alpha)$ Fractional-order transfer functions to approximate low-pass magnitude responses with arbitrary quality factor", AEU - International Journal of Electronics and Communications, vol. 78, pp. 1-10, 2017. DOI: 10.1016/j.aeue.2017.04.031.

[18] T. Dostal, "Filters with multi- loop feedback structure in current mode", Radioengineering, vol. 12, no. 3, pp. 6-11, 2003. [Online]. Available: http://hdl.handle.net/11012/58100

[19] R. Sotner, N. Herencsar, J. Jerabek, R. Prokop, A. Kartci, T. Dostal, K. Vrba, "Z-copy controlled-gain voltage differencing current conveyor: advanced possibilities in direct electronic control of firstorder filter", Elektronika ir Elektrotechnika, vol. 20, pp. 77-83, 2014. DOI: 10.5755/j01.eee.20.6.7272.

[20] J. Jerabek, J. Koton, R. Sotner, K. Vrba, "Adjustable band-pass filter with current active elements: two fully-differential and single-ended solutions", Analog integrated circuits and signal processing, vol. 74, pp. 129-139, 2013. DOI: 10.1007/s10470-012-9942-4.

[21] J. Jerabek, R. Sotner, K. Vrba, "Electronically adjustable triple-input single-output filter with voltage differencing transconductance amplifier", Revue Roumaine des Sciences Techniques - Serie Électrotechnique et Énergétique, vol. 59, pp. 163-172, 2015. 